\title{
“ORGULHO DE SER HETERO”? disputas em torno das masculinidades em uma página do Facebook
}

Carin Klein

Alison dos Santos

\begin{abstract}
Resumo
O presente trabalho tem como objetivo analisar a produção e a veiculação de representações de masculinidades e de feminilidades em uma página do Facebook, intitulada "Orgulho de ser Hetero". O estudo insere-se nos campos teóricos dos Estudos Culturais e Estudos de Gênero, em aproximação com a perspectiva pós-estruturalista. Para a operacionalização da pesquisa, selecionamos um conjunto de imagens e textos, a fim de explorá-los a partir dos conceitos de cultura, representação e gênero, com a intenção de discutirmos as representações de gênero que estão sendo ali veiculadas, ou seja, realizamos o exame de como elas vêm sendo nomeadas, reforçadas, re/atualizadas, tensionadas e negociadas, por meio dos sentidos que se incorporam a elas nesse contexto.
\end{abstract}

Palavras-chave: cultura; representação; gênero; masculinidade.

\section{“ORGULHO DE SER HETERO"? disputes over masculinities on a Facebook page}

This paper abstract This paper aims to analyze the production and serving of representations of masculinities and femininities on a Facebook page, entitled "Orgulho de ser Hetero". The study is inserted in the theoretical fields of Cultural Studies and Gender Studies, in approximation with the post-structuralist perspective. For the operationalization of the research, we selected a set of images and texts, in order to explore them from the concepts of culture, representation and gender, with the intention of discussing the gender representations that are being transmitted there, that is, we carried out the examination of how they have been named, reinforced, re/updated, tensioned and negotiated, through the meanings that are incorporated to them in this context.

Keywords: culture; representation; gender; masculinity.

\section{“ORGULHO DE SER HETERO”? disputas sobre masculinidades en una página de Facebook}

Resumen

Este trabajo tiene como objetivo analizar la producción y colocación de representaciones de masculinidades y feminidades en una página de Facebook, titulada "Orgulho de ser hetero". El estudio se inserta en los campos teóricos de Estudios Culturales y Estudios de Género, en aproximación a la perspectiva postestructuralista. Para la operacionalización de la investigación, seleccionamos un conjunto de imágenes y textos, a fin de explorarlos desde los conceptos de cultura, representación y género, con la intención de discutir las representaciones de género que se transmiten allí, es decir, llevamos a cabo el examen de cómo han sido nombrados, reforzados, re/actualizados, tensados y negociados, a través de los significados que se les incorporan en este contexto.

Palabras clave: cultura; representación; género; masculinidad. 


\section{INTRODUÇÃO}

O ciberespaço tem se apresentado de forma ambivalente: ora como renovação da sociedade por meio da dissolução das fronteiras, da participação e cooperação dos indivíduos, da inovação e da criatividade, ora como um caminho íngreme em direção a posições que pretendem apagar o diverso, ou seja, investindo na ampliação de noções essencialistas, no fortalecimento de extremismos, na pornografia, e acrescentaríamos, na homofobia (LOVELUCK, 2018, p. 92). Não se trata aqui de marcar formas que se opõem, e sim que coexistem.

Nesta perspectiva, produzem-se áreas de estudo e de reflexão para tratarmos de questionamentos que emergem da ascensão da cibercultura, entendendo-a como um local potente de análise, na medida em que atua na constituição do que passamos a chamar de humano. Podemos dizer que desde a década de 1990 vivemos em um tempo marcado por diversas transformações no âmbito cultural, como a ampliação de conteúdos em diversas e disseminadas tecnologias digitais que, por sua vez, atuam na constituição de comportamentos, relacionamentos, sentimentos, atitudes, ou seja, proliferam formas de educar que muitas vezes passam despercebidas do nosso olhar, na medida em que naturalizamos determinadas práticas sociais.

É, assim, que propomos, neste texto, analisar a página do Facebook "Orgulbo de ser Hetero", tomando-a como um espaço virtual que opera no sentido de educar os sujeitos a viver masculinidades e feminilidades, bem como a assumir determinadas formas de se relacionar afetivamente e sexualmente. Esta página possui mais de um milhão e meio de seguidores na rede social e iniciou em resposta ao fortalecimento das paradas LGBT no Brasil afora, ${ }^{1}$ principalmente a que ocorreu/ocorre em São Paulo, e vem desde então promovendo discursos de ódio em suas postagens, abusando de conteúdos de cunho homofóbico, misógino e machista, além de veicular representações femininas ligadas à sexualização e objetificação. Ao mesmo tempo, reitera e faz uso constante de enunciados heteronormativos e de amor romântico, nos quais mulheres e homens são posicionados em lugares distintos e complementares.

Somente no Brasil, a rede social conta hoje com mais de 100 milhões de usuários (SUMARES, 2016), que compreendem todas as faixas etárias. Dentro desta rede social, os/as usuários/as agrupam-se em diversas páginas de acordo com suas áreas de interesse, produzindo, disponibilizando e interagindo, a partir de conteúdos diários. Entendemos que o conteúdo que é disponibilizado através de páginas, como a que nos propomos analisar, veicula discursos provenientes de diferentes campos do conhecimento, assim como do senso comum, a fim de produzir e reatualizar lições por meio das formas de nomear, posicionar, definir, estabelecer normas, regular condutas, instituir significados e criar subjetividades em torno do gênero e da sexualidade.

Não devemos subestimar a importância que estes locais ocupam em nossa cultura, na medida em que entendemos que tanto o gênero como a sexualidade são construtos da cultura, ou seja, nessa construção estão implicados os símbolos, as instituições, as leis, as normas, as funções, os sentimentos, os comportamentos, etc., divulgados e instituídos, por meio da linguagem (MEYER, 2013). Desse modo, a escrita parte de um lugar que tem como objetivo desnaturalizar e problematizar alguns significados atrelados às relações de gênero; porém, ao considerarmos a

\footnotetext{
1 A Parada do Orgulho Gay de São Paulo se iniciou no ano de 1997, ocorre na Avenida Paulista e objetiva dar visibilidade e representatividade aos movimentos LGBT, assim como ao combate à homofobia. É também um evento cultural, tendo seu nome alterado em 1999 para Parada do Orgulho LGBT. No ano de 2013 chegou a atingir quatro milhões de participantes, segundo os organizadores. Faz parte do calendário da cidade, atraindo turistas de várias partes do mundo. Este modelo de manifestação disseminou-se posteriormente para várias cidades do Brasil.
} 
centralidade da linguagem, recorrente nessa perspectiva, admitimos que somos partes integrantes desses processos, sem escapar das formas de produção de conhecimentos, poder e regulação daquilo que nos propomos a analisar.

\section{APRESENTANDO AS FERRAMENTAS TEÓRICO-METODOLÓGICAS}

Para a realização das análises e do recorte do material empírico para este trabalho, partimos de compreensões importantes, aliadas aos campos teóricos dos Estudos Culturais e dos Estudos de Gênero, em aproximação com a perspectiva pós-estruturalista. A primeira diz respeito ao conceito de cultura, que aqui é tomada como um conjunto de significações que os seres humanos atribuem às suas práticas cotidianas e às suas vidas em sociedade. Vale dizer que a produção de sentidos, no âmbito da cultura, ocorre por meio dos processos educativos e de socialização e estão imersos em relações de poder e contestação, na medida em que elegemos e/ou selecionamos o que conta ou não como conhecimento a ser ensinado/veiculado. Desse modo, a ação social é fundamentalmente cultural (HALL, 1997).

Em segundo, utilizamos o conceito de representação, que está centralmente aliado ao caráter produtivo, fluido e indeterminado da linguagem. A representação "[...] inclui as práticas de significação e os processos simbólicos por meio dos quais os significados são produzidos, posicionando-nos como sujeito" (WOODWARD, 2007, p. 17). E mediante os significados produzidos por intermédio das representações que damos sentido à nossa experiência e àquilo que nos tornamos.

Em terceiro, nos dispomos a usar o conceito de gênero como ferramenta teóricometodológica, pois ela nos encaminha às análises de "[...] todas as formas de construção social, cultural e linguística implicadas com processos que diferenciam mulheres de homens, incluindo aqueles processos que produzem seus corpos, distinguindo-os e nomeando-os como corpos dotados de sexo, gênero e sexualidade" (MEYER, 2004, p. 15). Nessa linha, investimos em análises cuja intenção reside no questionamento, na dúvida e/ou na modificação, mesmo que minimamente, de relações sociais instituídas, ao colocar determinadas representações sob suspeita, evidenciando o seu caráter provisório, construído e interessado.

Esses pressupostos nos permitem dizer que as masculinidades e as feminilidades são compreendidas aqui como processos dinâmicos e inacabados, ligados a arranjos sociais que buscam nomear, educar e posicionar os indivíduos como sujeitos masculinos e femininos. Por serem plurais, a forma de viver o gênero indica as disputas, as divergências e o caráter relacional com que se constituem essas posições, em meio a diferenciais de poder, como por exemplo, diferentes marcadores sociais, podendo repercutir também de modo conflituoso e múltiplo em diferentes lugares e momentos da vida. Nessa perspectiva, masculinidades e feminilidades não são um a priori, tampouco são naturais ou coladas à vida e aos corpos de homens e mulheres. Ou seja, partimos do entendimento que masculinidades e feminilidades são fenômenos discursivos implicados em campos de produção de sentidos, sujeitos à disputa e negociação de condutas, regras e comportamentos sociais vivenciados pelos indivíduos em diferentes tempos (ALMEIDA, 1996).

Na perspectiva adotada, a sexualidade também não corresponde a um corpo masculino e/ou feminino, não é compulsória ao gênero, tampouco cabe numa ordem binária. Compreendidos enquanto construtos, o desejo e a sexualidade podem desprender-se das normas e do que nomeamos como natureza, podem multiplicar-se, resistir, reinventar-se, isto é, escapar de uma "[...] inteligibilidade cultural pelos quais todos deveriam ser definidos” (LOURO, 2004, p. 67). Então, 
interessa-nos o exame dos regimes de poder e de verdade que investem, educam e inscrevem nos sujeitos determinadas formas de viver o gênero e a sexualidade, ora como "seguras" e "adequadas", ora como "desvios" e/ou "problemas" que necessitam de correção.

Segundo Rosa Fischer (2001), devemos nos afastar de explicações lineares, unívocas, fáceis ou de uma busca por verdades totalizantes, capazes de explicar e/ou justificar determinados lugares e posições sociais para os sujeitos. Diante da "realidade" social precisamos afirmar uma postura intelectual de desconfiança e inquietude, a fim de perscrutar os processos culturais que incidem sobre os sujeitos e remetem à construção de determinadas representações, colocando em evidência a necessidade de um escrutínio sobre as "[...] práticas sociais em sua continuidade histórica mergulhadas em relações de poder, produzidas discursivamente e ao mesmo tempo produtoras de discursos e de saberes" (FISCHER, 2001, p. 201). Nessa direção, a autora reforça a inexistência de verdades ou sentidos ocultos aguardando por revelação; há sim um feixe de relações históricas imersas em relações de poder, a concretude de orientações e ensinamentos que se valem de determinadas formas de narrar, nomear e valorar as relações, os comportamentos e os sentimentos, por exemplo, necessitando dar visibilidade à materialidade que os produzem.

Investigar as masculinidades em diferentes espaços da vida social, tal como realizamos nessa investigação, ganham centralidade e relevância devido ao caráter constitutivo da cultura, como já indicamos, uma vez que é nela que circulam e atuam os processos discursivos e simbólicos (BANDEIRA, 2010; JAEGER, JACQUE, 2017; NASCIMENTO, 2016; TAGLIAMENTO, TONELI, 2010). O que tais processos explicitam, e nos interessam especialmente, são as evidências do quanto às representações de masculinidades operam nesses contextos, enquanto reguladores dos corpos e dos modos de agir, sentir, consumir, comportar-se e ocupar determinados lugares, mas, sobretudo, da produtividade de examinar as masculinidades (e o gênero) enquanto construtos, muitas vezes relacionadas a interesses e demandas de diferentes tempos e contextos sócio-políticos.

Com este artigo, buscamos articular a discussão entre cultura e gênero, a fim de evidenciarmos o caráter constitutivo das representações de masculinidades e feminilidades, veiculadas em uma página do Facebook. Assumimos a página "Orgulho de ser Hetero" como um artefato, interessado em veicular, difundir e naturalizar sentidos específicos para determinadas formas de viver de homens, mulheres, famílias e parentalidades. Pensamos ser necessário evidenciar a veiculação e o fortalecimento das representações de gênero e sexualidade divulgadas na página, enquanto opostas e completares entre si, o que indica um caráter de luta e de representatividade, justificadas por um suposto caráter universal e heteronormativo.

Estudos que envolvem a discussão sobre masculinidades e mídias (BEIRAS et al. 2007; CARVALHO, SIQUEIRA, 2007; FARO et al, 2013; ZAGO, 2009) nos encaminham a perspectivas analíticas sobre as representações das masculinidades em diferentes espaços midiáticos, relacionadas aos corpos, às sexualidades, ao consumo, à saúde, etc. Essas investigações descrevem e problematizam a produção de determinadas normas, estéticas e sociabilidades que se ora se afastam, ora se aproximam de uma suposta matriz cisheteronormativa. Ao examinarmos a mídia, mais precisamente, a página "Orgulho de ser Hetero" do Facebook, filiamo-nos a esses/as autores/as, a fim de problematizá-la enquanto um local importante de enunciação, de produção de sentidos, de disputas políticas em torno do poder e da significação, acerca da produção das masculinidades contemporâneas.

Nesse sentido, a produção e a organização do material empírico ocorreram ao longo do primeiro semestre de 2018. Em um primeiro movimento, exploramos o que era dito, na página do Facebook, por quem e em que circunstâncias; em um segundo movimento, identificamos a produtividade dos materiais para as análises, na qual realizamos uma seleção de imagens, frases e 
interações que consideramos produtivas para as discussões. Por fim, agrupamos e selecionamos os materiais para as análises, a partir dos seguintes focos: a) de que forma as representações de masculinidade e feminilidade tornam-se des/valorizadas nesse contexto; b) quais as características, comportamentos e atividades homens e mulheres necessitam aprender e incorporar, a fim de adequar-se a uma suposta norma cishetoronormativa; c) quais os efeitos de poder que elas incorporam e/ou colocam em circulação. Vale dizer que o caminho da pesquisa, desde a perspectiva teórica que assumimos, não se compromete com a verdade dos fatos e das coisas, mas, fundamentalmente, em contar uma história e colocar alguns de seus elementos em suspeição, sem perder o rigor metodológico.

Para cumprir esse fim, organizamos o texto nas seguintes partes: a introdução da discussão; as ferramentas teórico-metodológicas que nos permitem discutir e evidenciar o caráter construído da representação e do gênero; o exercício analítico que coloca sob suspeita determinados comportamentos, sentimentos, prazeres, funções e subordinações ali divulgadas, como se algumas fossem inerentes, fixas ou próprias de mulheres ou de homens, justificando assimetrias de gênero e poder; e, por fim, algumas considerações a fim de ampliar a reflexão sobre os processos educativos que estamos imersos.

\section{“ORGULHO DE SER HETERO”?}

Iniciamos a discussão colocando em dúvida a frase que intitula a página analisada. Esse movimento suspeita da necessidade de reiteração de uma norma de gênero e de sexualidade que pretende valorizar uma determinada forma de viver a masculinidade e a feminilidade, ao mesmo tempo em que despreza e se afasta de outras. Ao desnaturalizarmos essas representações de gênero e sexualidade, pretendemos mostrar o seu caráter histórico, dinâmico e de produção. Como já indicamos, desnaturalizá-las, no âmbito deste estudo, nos encaminha a evidenciar as formas como elas são reiteradas, classificadas, valoradas, hierarquizadas, ou seja, significa estranhar e questionar essa configuração.

Os conceitos de gênero e sexualidade nos permitem produzir algumas indagações, tais como: de que forma o conteúdo dessa página pode corroborar para a sustentação de uma lógica binária dos gêneros? Quais representações de feminilidades/masculinidades tornam-se des/valorizadas nesse contexto? Quais são os efeitos de poder que essas representações produzem e fazem circular?

Nesse sentido, torna-se emblemático o uso da foto de perfil da página, que exibe a imagem do ator americano Charlie Sheen, primeiro protagonista da série "Two and a Half Men", ${ }^{2}$ reconhecido devido a construção de sua fama de mulherengo, volúvel, bêbado e bem-sucedido na carreira, elementos que concorrem com a sua vida longe das telas, ou seja, o envolvimento com as drogas, o uso da violência com suas mulheres e vários outros escândalos sexuais, atitudes que lhe conferiram uma espécie de troféu, tornando-o uma espécie de ícone do orgulho masculino e heterossexual.

Ao pensarmos sobre quem e o que representa a masculinidade nas imagens e frases postadas na página do Facebook "Orgulho de ser Hetero", nos chama a atenção o fato de haver representações, repetidamente valorizadas, por meio de imagens (conforme Figura 1 e 2) que corroboram para consagrar a representação de masculinidade branca, de meia idade, vestido como executivo, seguidas

\footnotetext{
2 "Two and a Half Men" é uma série de sucesso da televisão norte-americana. Estreou em setembro de 2003 e encerrou em fevereiro de 2015, após 12 temporadas.
} 
de frases que reforçam a masculinidade vinculada à heterossexualidade, virilidade, força, resistência, dureza e uma posição econômica privilegiada.

Figuras 1 e 2: Representações de masculinidade

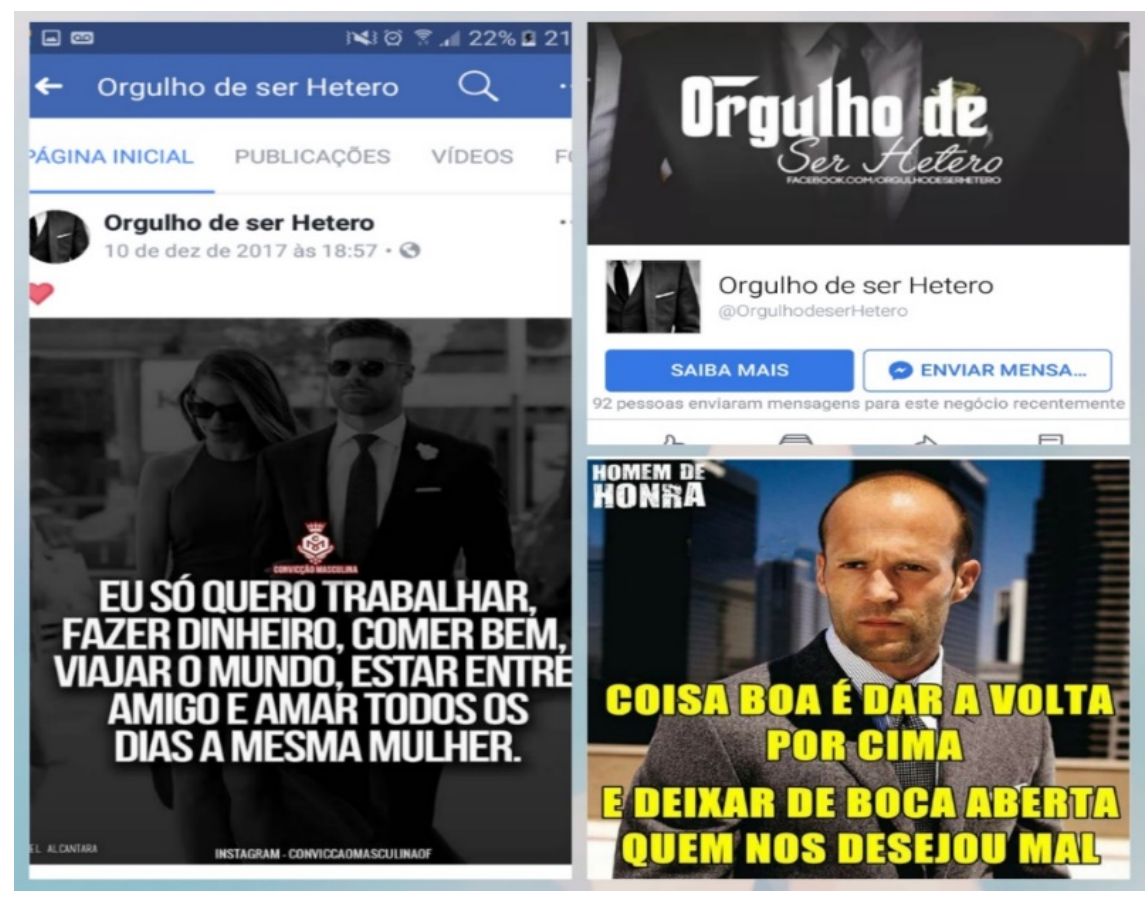

Fonte: Orgulbo de ser Hetero, $2018^{3}$

A masculinidade hegemônica pode ser compreendida por um conjunto de práticas e normas de gênero que legitimam uma posição dominante de determinados homens em nossa sociedade, ao mesmo tempo em que, nesse jogo, produz masculinidades de menor prestígio (CONNELL, 1995). Desta maneira, forma-se uma hierarquização em torno das masculinidades em nossa cultura, de um lado e com maior prestígio, aquelas associadas à força, valentia, comando, sucesso profissional, e, em outras, formas invisibilizadas ou tomadas como marginais, como, por exemplo, do homem gay, pobre, fraco, efeminado, sensível, uma vez que essas representações contrastam e confrontam os pressupostos da masculinidade hegemônica e heteronormativa, divulgada recorrentemente na página analisada.

Cabe refletir sobre o processo de fortalecimento e re/afirmação da identidade masculina heterossexual, ao investir na produção de aproximações e de afastamentos, ora do que é entendido ali como um homem másculo e bem-sucedido, ora do que é tomado como um homem fraco e capaz de colocar em xeque o que se pretende ali reforçar. Se trabalharmos na perspectiva de que não há uma noção de completude, assim como de essência e finitude nas identidades humanas, ser homem e heterossexual está constantemente em disputa, dispersão e descontinuidade, ou seja, em permanente negociação no âmbito da cultura. (CONNELL, MESSERSCHMIDT, 2013).

\footnotetext{
3 A imagem foi elaborada pelo/a autor/a, por meio de capturas de tela da página do Facebook "Orgulho de ser Hetero".
} 
Como já argumentamos, ao adotarmos a perspectiva das análises feministas, ligadas ao pósestruturalismo, assumimos que as identidades e as diferenças de gênero são construções discursivas, importando-nos identificar e discutir o caráter produzido das oposições homem/mulher, masculinidade/feminilidade, fraco/forte, chamando a atenção para o fato de que essas categorias são provisórias, relacionais, podem borrar-se e são produtos de uma determinada cultura. Essa compreensão aponta o caráter conflituoso e contingente que está envolvido na atividade de significação e, portanto, na formação do gênero.

Connell (1995) evidencia que a construção de uma masculinidade hegemônica tem a função de atuar como um elemento exemplar, organizador e regulador na cultura, mesmo que poucos homens consigam reconhecer-se nela. E acrescenta:

Se gênero é um produto histórico, então ele está aberto à mudança histórica [...]. Nessa narrativa, toda cultura tem uma definição da conduta e dos sentimentos apropriados para os homens. Os rapazes são pressionados a agir e a sentir dessa forma e a se distanciar do comportamento das mulheres, das garotas e da feminilidade, compreendidas como o oposto. A pressão em favor da conformidade vem das famílias, das escolas, dos grupos de colegas, da mídia e, finalmente, dos empregadores. A maior parte dos rapazes internaliza essa norma social e adota maneiras e interesses masculinos, tendo como custo, frequentemente, a repressão de seus sentimentos. Esforçar-se de forma demasiadamente árdua para corresponder à norma masculina pode levar à violência ou à crise pessoal e a dificuldades nas relações com as mulheres (CONNELL, 1995, p. 189-190).

Em outra imagem selecionada (Figura 3), analisamos um conjunto de enunciados, cujo título é: "Como identificar um homão da porra!" que, no caso, saberá realizar "com maestria" determinados comportamentos, funções e a vivência de sentimentos relacionados à masculinidade.

Figura 3: Como identificar um homão da porra!

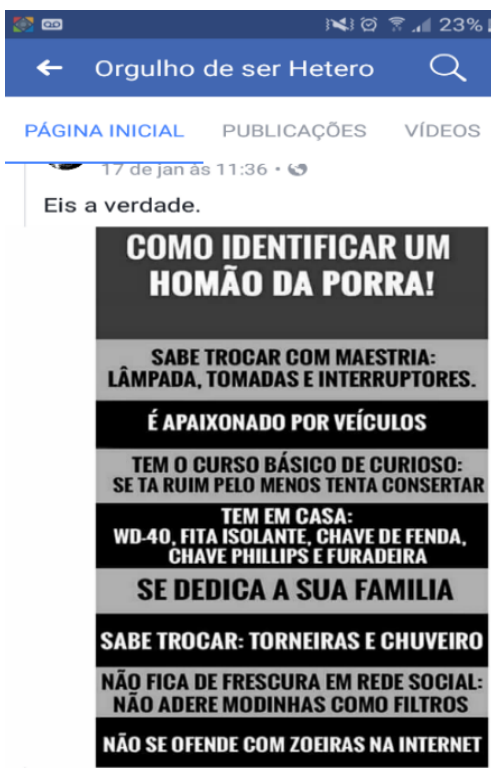

Fonte: Orgulho de ser Hetero, 2018 
"Um homão da porra" necessita incorporar determinados ensinamentos, ou seja, habilitarse a trocar as lâmpadas, tomadas e interruptores, torneiras e chuveiro, ser apaixonado por veículos, ter o "curso básico de curioso" para, pelo menos, aprender a consertar (caso não saiba), ter em casa os recursos para esses fins (fita isolante, chave de fenda, chave Philips e furadeira), além de dedicarse a sua família. Esse homem também não deve ficar de "frescura em rede social", "aderir a modinhas", como fazer perfil de casal, ou "ofender-se com zoeiras na internet". Com isso, pode-se dizer que vai se compondo um vasto repertório considerado "adequado", cujos sentidos são travados em meio as relações de socialização que envolvem o gênero e a sexualidade.

Ao serem compartilhadas e constantemente reafirmadas (com likes, compartilhamentos e comentários), as representações de masculinidade em torno de um "homão da porra" pretendem atuar na construção de regimes de verdades, nomeando, exaltando, consolidando, disputando e, ainda, como já dissemos, afastando-se e entrando em tensão com outras formas de viver a masculinidade. Por meio dos enunciados, seus seguidores podem reafirmar-se, reconhecer-se, diferenciar-se e subjetivar-se a partir de uma suposta norma que busca operar e constituir formas de ser, agir, sentir e viver o gênero e a sexualidade. Com um caráter imperativo, a linguagem ali divulgada hierarquiza e exclui as representações de masculinidades que não se enquadram, ou seja, ser um "homão da porra" e sentir "orgulho de ser hetero" passam a funcionar como identificadores, capazes de marcar quem se aproxima dessas representações, mas também capaz de marcar aqueles que se opõem, se afastam ou se diferenciam, sendo considerados então "menos homens" no âmbito da página aqui analisada.

A masculinidade torna-se um processo que necessita ser constantemente vigiado, reiterado e ligado a uma lógica de sexo-gênero-sexualidade. Supõe-se o sexo como um dado, anterior à cultura e capaz de reger compulsoriamente uma forma única e natural de viver a sexualidade e o desejo (LOURO, 2004; KLEIN, VARGAS, 2019).

A "mulher ideal" e o "amor romântico" também se tornam recursos retóricos importantes dessa página do Facebook, capazes de atribuir sentidos específicos à masculinidade e à feminilidade, conforme vemos nas imagens a seguir (Figuras 4 e 5): 
Figura 4: Mulher ideal

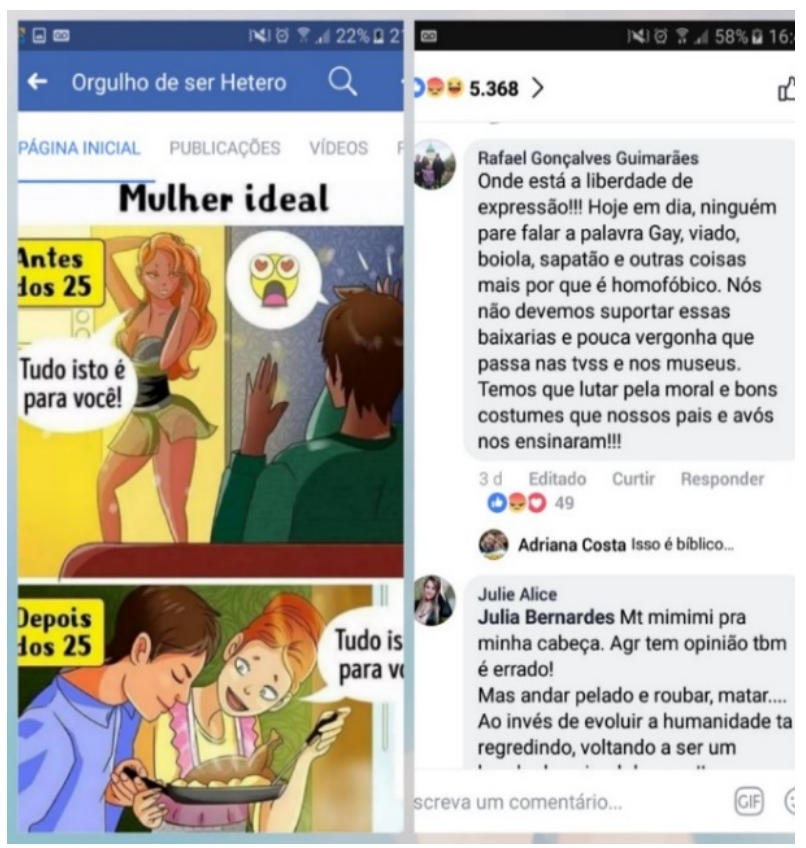

Fonte: Orgulho de ser Hetero, 2018
Figura 5: Românticos?

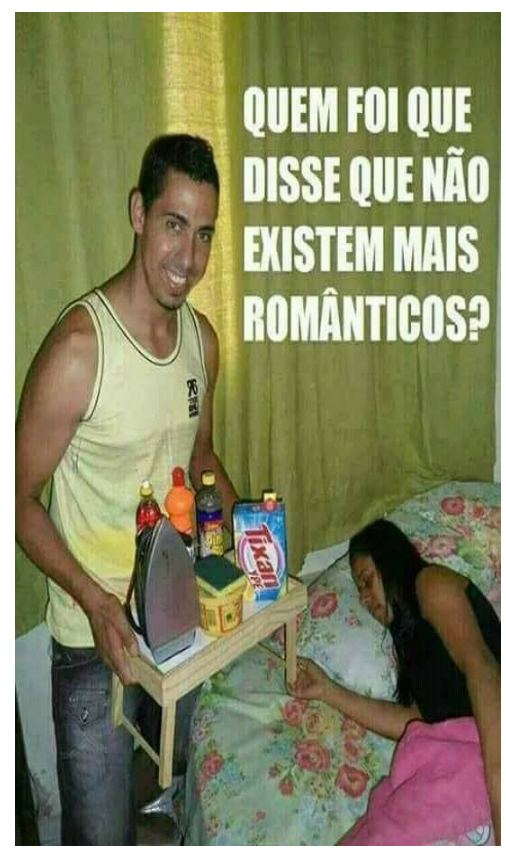

Fonte: Orgulho de ser Hetero, 2018

Para a construção dessa representação de masculinidade é apresentada a "mulher ideal" (Figura 4) que a ele corresponde. Ela "antes dos 25 anos" seria aquela que possui um determinado padrão de beleza, sensualidade e feminilidade, ou seja, cintura fina, peitão, cabelos loiros e longos, usando roupas curtas; porém, com o passar do tempo, "após os 25 anos", a "mulher ideal" é representada ligada ao âmbito privado, preocupada com o bem-estar do companheiro e à disposição para lhe servir, suas roupas e cabelos modificam-se, agora presos, parecem evidenciar um comportamento mais recatado e típico da mulher para casar. Nesse jogo discursivo, a construção dessas representações de feminilidade, associadas ao amor romântico, parecem complementar uma suposta norma que precisa ser instituída e reiterada, a fim de atuar na produção dessa masculinidade.

Para Jane Felipe (2007, p. 38), o amor romântico é "[...] regido por uma idealização que se estende aos seguintes aspectos: a ideia de intensidade (em si mesmo e no outro, para quem o amor se destina), a concepção de completude, de eternidade e de entrega". Viver esse amor romântico e idealizado passa a fazer parte de um determinado projeto de família, relacionamento e sociedade, reafirmado reiteradamente pela publicidade, literatura, músicas, poesias, filmes, novelas, etc. e, em nome desse amor, acolhe-se e naturalizam-se relações assimétricas em torno da reprodução e das relações cotidianas que podem envolver a contracepção, o cuidado, a educação dos/as filhos/as, o trabalho doméstico, só para citar alguns (KLEIN, 2012; 2018).

Tal forma de viver o amor romântico também está, seguidamente, associada às experiências e sentimentos de entrega, abnegação de si em favor do outro, confiança, segredo, renúncia, dedicação, zelo, desejo e ideal a ser vivido. Para Felipe (2007), a produção deste ideal de amor romântico deve se tornar alvo de exame e de discussão, visto na sua transitoriedade, inconstância e fluidez que também o caracterizam. 
Como uma construção histórica e cultural, o amor, a paixão, bem como seus desdobramentos em termos de relação, merecem ser amplamente discutidos na perspectiva de uma educação para a sexualidade, e aqui utilizo essa expressão por entender que ela pode acionar discussões mais abrangentes quando se trata de refletir sobre nossos prazeres e desejos, não se restringindo ao sexual como ato, mas proporcionando outras vias de discussão e temáticas diversas, para além do viés biologicista (FELIPE, 2007, p. 42).

Também verificamos que são compartilhadas imagens que, ao mesmo tempo em que investem em uma representação da "masculinidade hétero", usam como recurso para essa construção o distanciamento de características consideradas em nossa cultura como femininas, desvalorizadas, portanto, em relação ao que nesse espaço é tomado como feminino. Desse modo, o "homem hétero" deve ter ainda uma forma de relacionar-se com as mulheres, em alguns momentos, evidenciando zelo, cuidando-a, mimando-a, levando-a para jantar, e, em outros, numa espécie de deboche ao "romantismo", servindo-a, com artefatos domésticos e de limpeza, que cumprirão a função de servi-lo, cuidá-lo, cuidar da casa, etc. (Figura 5).

A Figura 5 utiliza como recurso de imagem um homem sorridente que leva uma bandeja de café na cama a uma mulher que aparenta exaustão, servindo-lhe, em vez de café, variados produtos domésticos e de limpeza (ferro de passar roupa, esponja, sabão em pó, detergente). As frases e imagens indicam quase uma impossibilidade de compreendermos os homens como cuidadores e ligados às tarefas consideradas como "coisas de mulher". Fernando Seffner (2003, p. 116) argumenta que "[...] as questões de sexualidade e de gênero caminham próximas, num jogo de relações e influências recíprocas". Para esse autor, um dos aspectos importantes para as análises de gênero refere-se ao exame da "[...] organização social [e] das interações entre o masculino e o feminino, para além do terreno sexual", observando que as “[...] 'coisas de homem' e [as] 'coisas de mulher' aparecem impressas em situações muito alheias ao sexual propriamente dito". Assim, ao que concerne a discussão de gênero, torna-se produtivo pensarmos sobre o que está sendo apresentado como "coisas de homem" e "coisas de mulher", na medida em que essas vivências passam a ser entendidas a partir de determinadas marcas corporais (SEFFNER, 2003).

Vale ressaltar que é exatamente na seção de "comentários" de cada postagem que tais modelos hegemônicos de masculinidade são mais uma vez exaltados, exacerbados, valorizados e afirmados, em detrimento de masculinidades que são consideradas dentro deste contexto como inferiores, subordinadas, desvalorizadas e até desprezíveis, como já avaliamos. Os comentários dos seguidores, como podemos ver na Figura 4, geralmente salientam a necessidade de "lutar pela moral e bons costumes" da sociedade, aqueles que, segundo eles, "passam de pai para filho", a fim de exercer o que nomeiam como "liberdade de expressão" (e não homofobia) ao legitimar formas de viver a masculinidade que não se encaixam no padrão da página, no caso a masculinidade homossexual.

Investe-se em colocar como próprio do homem e da masculinidade comportamentos que "passam de pai para filho", numa retórica que busca essencializar como próprias do homem ou da cultura características ligadas à conquista, ao poder, à determinação, e finalmente à manutenção do "orgulho" em ser hetero. Desse modo, a página não tem lugar para os corpos que subvertem e não se conformam às regras de gênero e sexualidade ali divulgadas, assim como não há espaços para deslocamentos, desestabilidades e descaminhos tão conhecidos nos percursos escolares, institucionais e familiares, tão próximos de todos/as nós (MOTTA, FAVACHO, 2018). Não há vontade de visibilizar e compreender os sujeitos que cruzam as fronteiras ali estabelecidas, tampouco 
em arriscar-se e refletir sobre a produtividade da vida que nos escapa sempre, afetando-nos, alterando-nos. (DAL'IGNA, KLEIN, MEYER, 2016)

\section{PARA FINALIZAR}

Com este estudo encontramos a re/afirmação de representações de masculinidades, associadas à constituição de uma família nuclear, no qual o homem necessita ser bem-sucedido, além de exercer a autoridade e o comando nas relações. São essas características que são fortemente reiteradas para dar sentido à masculinidade ali divulgada. Argumentamos que a página "Orgulho de ser Hetero" tem atuado como uma instância educativa que opera no sentido de naturalizar e consolidar algumas formas de viver as masculinidades, historicamente consideradas hegemônicas, ao mesmo tempo em que, por meio de suas postagens, deslegitima, inferioriza e subordina outras formas de ser homem e que não correspondem a ela. Nessa direção, busca conformar e reconhecer noções essencialistas e binárias para o gênero e a sexualidade. Nada, nem ninguém, caberá fora desse binarismo de gênero e de sexualidade.

Valendo-se de discursos religiosos e políticos, no dia 10 de agosto de 2019, o Estadão traz a manchete com o seguinte título:a 'família tradicional' e chama 'ideologia de gênero' de 'coisa do capeta" (PUPO, WETERMAN, 2019, p. 1). Na ocasião, Bolsonaro, de cima do trio elétrico, ao participar da Marcha de Jesus, apoia-se na Bíblia e na atual Constituição Federal para reforçar sua candidatura à presidência da república, assumindo-se como o único que irá honrar a defesa da família tradicional e da inocência das crianças, rechaçando completamente as compreensões desenvolvidas nesse artigo. Cabe a nós também nos afastarmos e suspeitarmos de uma compreensão de infância tomada como pura ou inocente e que talvez, exatamente por isso, pode se tornar vulnerável (FELIPE, 2015). Acreditamos que devemos nos distanciar de movimentos conservadores que divulgam que o gênero e a sexualidade estão colados a uma suposta matriz biológica, assim como na página "Orgulho de ser Hetero", que não encontra lugar para relações que levem em conta o que é diverso, múltiplo, ambíguo, assim como para a pluralidade da vida humana.

Como nos diz Paula Sibilia (2004), assumir o caráter polifônico dos discursos significa pensar o sujeito, irremediavelmente, como um ser da linguagem, narrador-narrado.

\footnotetext{
O eu seria, portanto, uma entidade frágil e complexa, primorosamente costurada na linguagem: nas narrativas de si, a própria experiência adquire forma e conteúdo, ganha existência e se alicerça em torno de um determinado "eu". Esse impulso discursivo é um recurso fabuloso que os integrantes da espécie humana têm aprendido a utilizar para organizarem suas subjetividades e para se protegerem do fluxo caótico da vida. Usar palavras, logo, é agir. É criar universos e construir subjetividades, nutrindo o mundo com uma gama inesgotável de significações e sentidos. A qualidade performativa da linguagem não só organiza o tumultuado fluir da própria experiência e dá sentido ao mundo, mas também estabiliza o espaço e ordena o tempo, em diálogo constante com a multidão de outras vozes que também o modelam e o recheiam (SIBILIA, 2004, p. 3).
}

Se, para esses grupos, a ideologia de gênero significa falar sobre quem escapa de uma lógica heteronormativa e de uma suposta normalidade, em que todos se encaixariam, para nós isso significa silenciar sobre as vidas de pessoas que não se encaixam como masculinas ou femininas, não se adequando a uma sequência "natural", "dada" por um sexo biológico. Será que considerá-las desvio, 
anormais ou inferiores se constitui como um caminho aceitável a percorrer? Quais são os efeitos e as implicações para a vivência de feminilidades/masculinidades que não se reconhecem nessas representações? Quais os efeitos que a produção das representações de masculinidade, divulgadas na página "Orgulho de ser Hetero" podem trazer para os processos reprodutivos, assim como para as relações que cercam a paternidade e a conjugalidade? Neste estudo, não damos conta dessas indagações, mas indicamos o caráter educativo e político que envolve a constituição do gênero e da sexualidade.

\section{REFERÊNCIAS}

ALMEIDA, Miguel Vale de. Gênero, masculinidade e poder: revendo um caso do sul de Portugal. Anuário Antropológico, Rio de Janeiro, n. 95, p. 161-189, 1996.

BANDEIRA, Gustavo. Um currículo de masculinidades nos estádios de futebol. Revista Brasileira de Educação. v. 15, n. 44, 342-410, maio/ago. 2010.

BEIRAS, Adriano et al. Gênero e super-heróis: o traçado do corpo masculino pela norma. Psicologia \& Sociedade, 19 (3): 62-67, 2007.

CONNELL, Robert; MESSERSCHMIDT, James. Masculinidade hegemônica: repensando o conceito. Rev. Estud. Fem., v. 21, n. 1, p. 241-282, 2013.

CONNELL, Robert. Políticas da Masculinidade. Educação \& Realidade, Porto Alegre, v. 20, n. 2, p. 185-206, 1995.

DAL'IGNA, Maria Cláudia; KLEIN, Carin; MEYER, Dagmar. Generificação das práticas curriculares: uma abordagem feminista pós-estruturalista. Currículo sem Fronteiras, v. 16, n. 3, p. 468487, set./dez. 2016.

FARO, Livi et al. Homem com "H". Ideais de masculinidade (re)construídos no marketing farmacêutico. Cadernos Pagu (40), jan./jun. 2013: 287-321.

FELIPE, Jane. Do amor (ou de como glamourizar a vida): apontamentos em torno de uma educação para a sexualidade. In: RIBEIRO, Paula Regina Costa et al. (org.). Gênero e sexualidade: discutindo práticas educativas. Rio Grande: Editora da FURG, 2007. p. 31-45.

FELIPE, Jane. Erotização dos corpos femininos infanto-juvenis: um desafio para a educação de hoje. Revista Artificios, v. 2, p. 1-9, 2015.

FISCHER, Rosa Maria Bueno. Foucault e a análise do discurso em educação. Cadernos de Pesquisa, São Paulo, n. 114, p. 197-223, nov. 2001.

HALL, Stuart. A centralidade da cultura: notas sobre as revoluções culturais do nosso tempo. Educação \& Realidade, v. 22, n. 2, jul./dez. 1997. Disponível em http://www.gpef.fe.usp.br/teses/agenda 2011 02.pdf. Acesso em 14 mar. 2020.

JAEGER, Angelita Alice; JACQUES, Karine. Masculinidades e docência na educação infantil. Estudos Feministas, Florianópolis, 25(2): 562, maio/ago. 2017.

KLEIN, Carin. Educação de mulheres-mães pobres para uma "infância melhor". Rev. Bras. Educ., [online], v. 17, n. 51, p. 647-660, 2012.

KLEIN, Carin. Discursos que concorrem para a produção de infância e maternidade em políticas de inclusão social. Textura, Canoas, v. 20, n. 43, p 53-78, maio/ago. 2018. 
KLEIN, Carin; VARGAS, Juliana. Juventudes em campanhas de vacinação contra HPV e Meningite C - 2017 e 2018. In: CÚNICO, Sabrina, COSTA, Ângelo e STREY, Marlene. (org.). Gênero e Violência: Repercussões nos processos psicossociais e de saúde. Porto Alegre: EDIPUCRS, 2019, p. 525-550.

LOURO, Guacira Lopes. Um corpo estranho: ensaios sobre sexualidade e teoria queer. Belo Horizonte: Autêntica, 2004.

LOVELUCK, Benjamim. Redes, liberdades e controle: uma genealogia política da internet. Petrópolis: Vozes, 2018.

MEYER, Dagmar Estermann. Teorias e políticas de gênero: fragmentos históricos e desafios atuais. Rev. Bras. Enferm., [online], v. 57, n. 1, p. 13-18, 2004.

MEYER, Dagmar Estermann. Gênero e educação: teoria e política. In: LOURO, Guacira Lopes; NECKEL, Jane Felipe; GOELLNER, Silvana Vilodre. (org.). Corpo, gênero e sexualidade: um debate contemporâneo na educação. Petrópolis: Vozes, 2013.

MOTTA, Darci Aparecida Dias; FAVACHO, André Márcio. Do silêncio ao desconforto: a prática de educadoras da Educação Infantil diante da sexualidade das crianças. In: PARAÍSO, Marlucy Alves; CALDEIRA, Maria Carolina da Silva. (org.). Pesquisas sobre currículos, gêneros e sexualidades. Belo Horizonte: Mazza Edições, 2018, p. 241-259.

ORGULHO DE SER HETERO. 2020. Facebook: OrgulhodeserHetero. Disponível em https://www.facebook.com/OrgulhodeserHetero/. Acesso em 12 mar. 2020.

PUPO, Amanda; WETERMAN, Daniel. Bolsonaro defende a 'família tradicional' e chama 'ideologia de gênero' de 'coisa do capeta'. O Estado de São Paulo, Política, 10 ago. 2019.

RIBEIRO, Claudia Regina; SIQUEIRA, Vera. O novo homem na mídia: ressignificações por homens docentes. Estudos Feministas, Florianópolis, 15(1): 217-241, jan./abr., 2007.

SEFFNER, Fernando. Derivas da masculinidade: representação, identidade e diferença no âmbito da masculinidade bissexual. Tese (Doutorado em Educação), Programa de Pós-Graduação em Educação. Universidade Federal do Rio Grande do Sul, Faculdade de Educação, Porto Alegre, 2003.

SIBILIA, Paula. O 'eu' dos blogs e das webcams: autor, narrador ou personagem? In: CONGRESSO BRASILEIRO DE CIÊNCIAS DA COMUNICAÇÃO, 27, 2004. Anais... Porto Alegre: PUC-RS, 2004.

SUMARES, Gustavo. Facebook tem mais de 100 milhões de usuários brasileiros. Blog Olhar Digital, 2016. Disponível em https://olhardigital.com.br/noticia/facebook-tem-mais-de-100-milhoes-deusuarios-brasileiros/57706. Acesso em 12 mar. 2020.

TAGLIAMENTO, Grazielle; TONELI, Maria Juracy. (Não)trabalho e masculinidades produzidas em contextos familiares de camadas médias. Psicologia \& Sociedade; 22 (2): 345-354, 2010.

WOODWARD, Kathryn. Identidade e diferença: uma introdução teórica e conceitual. In: SILVA, Tomaz Tadeu da. (org.). Identidade e diferença: a perspectiva dos estudos culturais. 7. ed. Petrópolis: Vozes, 2007.

ZAGO, Luiz Felipe. Masculinidades disponiveis.com: Sobre como dizer-se homem gay na internet. Dissertação (Mestrado em Educação), Programa de Pós-Graduação em Educação. Universidade Federal do Rio Grande do Sul, Faculdade de Educação, Porto Alegre, 2009. 
DOI: $10.12957 /$ teias.\%Y.49609

\section{Informações dos autores}

\section{Carin Klein}

Professora no PPGEDU da Universidade Luterana do Brasil. ULBRA. Canoas/RS

E-mail: carinklein31@gmail.com

ORCID: https://orcid.org/0000-0002-1455-4413

Link Lattes: http://lattes.cnpq.br/7168696937800022

\section{Alison dos Santos}

Bolsista voluntário de iniciação à pesquisa no Programa de Pós-Graduação em Educação - ULBRA.

Canoas/RS.

E-mail: alison.historia@hotmail.com

ORCID: https://orcid.org/0000-0001-9379-4003

Link Lattes: http://lattes.cnpq.br/9347670963702245 